\title{
Journal of

\section{Facile synthesis of LTA molecular sieve membranes on covalently functionalized supports by using diisocyanates as molecular linkers $\dagger$}

\author{
Aisheng Huang and Jürgen Caro* \\ Received 12th April 2011, Accepted 26th May 2011 \\ DOI: 10.1039/c1jm11549a
}

\begin{abstract}
Much effort has been paid towards the preparation of hydrophilic zeolite LTA membranes, and these zeolite LTA membranes have showed excellent performance in hydrophilic separations. However, there are only a few reports on successful shape-selective separations of gas mixtures on zeolite LTA membranes, most separation factors reported so far were lower than the corresponding Knudsen constants. It is often found that zeolite LTA membranes contain inter-crystalline defects to degrade their separation selectivity, which result from the problems that the isolated crystals on the support surface grow together to form a continuous supported LTA layer. In the present work, via urethane bonds formed by the reaction of isocyanate groups with surface hydroxyls, a facile synthesis method is developed for the seeding-free preparation of supported dense zeolite LTA layers by using 1,4-diisocyanate as a molecular binder to anchor the zeolite nutrients onto the support surface. The $\alpha-\mathrm{Al}_{2} \mathrm{O}_{3}$ supported zeolite LTA membrane with a thickness of about $3.5 \mu \mathrm{m}$ displays molecular sieving performance in gas permeation tests.
\end{abstract}

\section{Introduction}

In the last 25 years, supported zeolite membranes have attracted intense interest as potential separators, reactors, sensors and electrical insulators due to their uniform pore structure and high thermal stability. ${ }^{1-6}$ So far, various types of supported zeolite layers, such as MFI, ${ }^{7,8}$ DDR,${ }^{9}$ LTA,${ }^{10-14}$ FAU $,{ }^{15,16} \mathrm{CHA},{ }^{17,18}$ and $\mathrm{AFI},{ }^{19}$ have been successfully prepared on different supports. Among these molecular sieve membranes, the zeolite LTA membrane is of special interest. On the one hand, the zeolite LTA membrane with a pore size of about $0.4 \mathrm{~nm}$ for $\mathrm{Na}^{+} \mathrm{LTA}$ (4A) is expected to be a candidate for the separation of small molecules such as hydrogen. ${ }^{12-14}$ By ion exchange, the pore size of LTA can be engineered: about $0.3 \mathrm{~nm}$ for $\mathrm{K}^{+} \mathrm{LTA}(3 \mathrm{~A})$ and about $0.5 \mathrm{~nm}$ for $\mathrm{Ca}^{2+}$ LTA (5A). On the other hand, zeolite LTA displays a strong hydrophilicity and allows us to remove water from organic solutions. ${ }^{20-25}$ Therefore, zeolite LTA membranes show excellent performance in hydrophilic separations, and are produced at an industrial scale for the de-watering of bio-ethanol. ${ }^{26,27}$

However, there are only a few reports on successful shapeselective separations of gas mixtures on zeolite LTA membranes, all separation factors reported so far were lower than the Knudsen constant with the exception of the $\mathrm{O}_{2} / \mathrm{N}_{2}$ separation ${ }^{28}$

Institute of Physical Chemistry and Electrochemistry Leibniz University of Hannover, Callinstraße 3-3A, D-30167 Hannover, Germany. E-mail: juergen.caro@pci.uni-hannover.de; Fax: +49-511-762 1912; Tel: +49511-7623175

$\dagger$ Electronic supplementary information (ESI) available: SEM, XRD, and measurement equipment. See DOI: 10.1039/c1jm11549a and our recent report of zeolite LTA membranes prepared on modified supports. ${ }^{12}$ It is often found that zeolite LTA membranes contain inter-crystalline defects, which result most probably from the problems that the isolated LTA crystals on the support surface cannot intergrow well to a continuous LTA layer. Because of the strong negative surface charge ( $\zeta$ potential), it is believed that negatively charged silicate/ aluminate building blocks are difficult to enter the narrow gaps between the LTA crystals. ${ }^{29}$ Another problem is the huge irregular changes of the unit cell if the LTA or FAU membranes become activated for permeation by drying. This shrinking and expansion can be two orders of magnitude larger than the thermal expansion behaviour which can also create inter-crystalline gaps and a mismatch of the zeolite layer with the support. $^{30}$ Due to these inter-crystalline gaps, gas transport through the membrane is controlled by Knudsen diffusion rather than by a molecular sieve mechanism. Therefore, the synthesis of molecular sieve zeolite LTA membrane is still a challenge.

It is of great significance to fully understand the formation mechanism of zeolite membranes to control and optimize membrane growth. ${ }^{31-35}$ According to Myatt's proposition, ${ }^{33}$ the formation of a zeolite membrane can be attributed to four different ways (Fig. S1 $\dagger$ ): (i) formation of nuclei and their growth to crystals in the bulk solution followed by their attraction to and association with the substrate; (ii) formation of nuclei in the bulk solution, but diffusion to and accumulation on the support surface before significant growth has occurred; (iii) diffusion of amorphous aluminosilicate material to and concentration on the substrate, providing more favourable conditions for nucleation and growth in the vicinity of the surface; (iv) formation of nuclei 
on the support surface, followed by their growth. The formation road (iv) in combination with either (ii) or (iii) is assumed to be the most probable mechanism for membrane formation. ${ }^{31-35}$ Therefore, the promotion of nucleation on the substrate surface is crucial to the membrane formation. It is well recognized that seed coating of the supports to offer nucleation centers is a powerful technique to direct nucleation and growth of the zeolite layers to obtain high performance zeolite membranes. ${ }^{36-39}$

Chemical modification of the supports surface to facilitate nucleation is another road for the seeding-free synthesis of highquality zeolite membranes. ${ }^{12,40}$ Recently, we have developed a novel strategy for the seeding-free preparation of zeolite LTA membrane by using 3-aminopropyltriethoxysilane (APTES) as a covalent linker between the zeolite layer and the porous $\alpha-\mathrm{Al}_{2} \mathrm{O}_{3}$ support. ${ }^{41}$ By covalent bonds, the LTA nutrients were attached to the support surface thus promoting the nucleation and growth of a continuous LTA layer. In pioneering studies, Yoon et al. and Biemmi and Bein proposed to improve the assembly of a zeolite film on a support by using 1,4-diisocyanate (DIC-4) as a molecular binder via the reaction of isocyanate groups with hydroxy groups. ${ }^{42,43}$ However, to the best of our knowledge, there is still no report on the preparation of molecular sieve membranes by using diisocyanates as molecular linkers until now. In the present work, we adopt and develop this concept for in situ growth of dense supported zeolite membranes/ layers on DIC-4 functionalized supports, as shown in Fig. 1. It can be expected that a zeolite LTA membrane prepared on a DIC-4 functionalized $\alpha-\mathrm{Al}_{2} \mathrm{O}_{3}$ support will be more perfect and show higher gas separation performances.

\section{Experimental}

\section{Materials}

Chemicals were used as received: LUDOX AS-40 colloidal silica (40\% $\mathrm{SiO}_{2}$ in water, Aldrich) as a $\mathrm{Si}$ source; aluminium foil (Fisher Scientific) as a Al source; sodium hydroxide $(>99 \%$, Merck); 1,4-diisocyanate (DIC-4, >97\%, Aldrich); 1,6-diisocyanate (DIC-6, $>98 \%$, Aldrich); and doubly distilled water. Asymmetric porous $\alpha-\mathrm{Al}_{2} \mathrm{O}_{3}$ disks (Fraunhofer Institute IKTS, former HITK/Inocermic, Hermsdorf, Germany: $18 \mathrm{~mm}$ diameter, $1.0 \mathrm{~mm}$ thickness, $70 \mathrm{~nm}$ particle size in the top layer), porous $\alpha-\mathrm{Al}_{2} \mathrm{O}_{3}$ tubes (Dalian Institute of Chemical Physics, CAS: $12 \mathrm{~mm}$ outside diameter, $9 \mathrm{~mm}$ inside diameter, $100 \mathrm{~mm}$ length, $c a$. $1.0 \mu \mathrm{m}$ pore size), non-porous glass plates $(18 \times$ $18 \times 1 \mathrm{~mm}$ ), non-porous polytetrafluoroethylene (PTFE) and

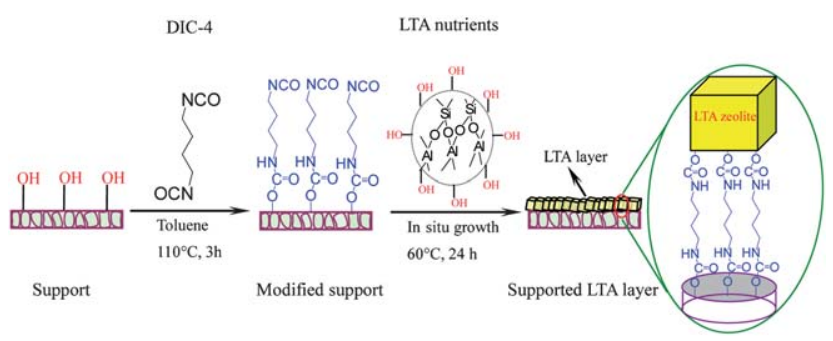

Fig. 1 Scheme of the synthesis of zeolite LTA membranes on covalently functionalized supports by using 1,4-diisocyanate (DIC-4) as molecular binders to in situ anchor LTA nutrients during hydrothermal synthesis. non-porous stainless steel disks $(18 \mathrm{~mm}$ diameter, $1.0 \mathrm{~mm}$ thickness) were used as supports.

\section{Preparation of zeolite LTA membranes/layers}

The zeolite LTA membranes/layers were prepared on covalently functionalized supports by using DIC-4/DIC-6 as a molecular binder to in situ anchor the formed nuclei during hydrothermal synthesis (Fig. 1). The porous or non-porous supports were treated with DIC-4/DIC-6 (0.1 M in $10 \mathrm{~mL}$ toluene) at $110^{\circ} \mathrm{C}$ for $3 \mathrm{~h}$ under argon, leading to a DIC-4/DIC-6 layer depositing on the supports surface. $^{42}$ For the synthesis of zeolite LTA membranes/layers, a clear synthesis solution with the molar ratio of $50 \mathrm{Na}_{2} \mathrm{O}: 1 \mathrm{Al}_{2} \mathrm{O}_{3}: 5 \mathrm{SiO}_{2}: 1000 \mathrm{H}_{2} \mathrm{O}$ was prepared according to the procedure reported elsewhere. ${ }^{12,41}$ The DIC-4/DIC-6 treated supports were horizontally placed face down $\left(\mathrm{Al}_{2} \mathrm{O}_{3}\right.$ tubes were placed vertically) in a Teflon-lined stainless steel autoclave which was filled with the synthesis solution. After hydrothermal synthesis of $24 \mathrm{~h}$ at $60{ }^{\circ} \mathrm{C}$, the solution was decanted off and the membrane was washed with deionized water several times, and then dried in air at $110{ }^{\circ} \mathrm{C}$ overnight for characterization and permeation measurements.

\section{Characterization of zeolite LTA membranes/layers}

SEM micrographs were taken on a JEOL JSM-6700F with a cold field emission gun operating at $2 \mathrm{kV}$ and $10 \mu \mathrm{A}$. The XRD patterns were recorded at room temperature under ambient conditions with a Bruker D8 VANDANCE X-ray diffractometer with the $\mathrm{CuK} \alpha$ radiation at $40 \mathrm{kV}$ and $40 \mathrm{~mA}$. Raman spectra were measured with a Horiba Jobin-Yvon T64000 triple-grating spectrometer, using the $\mathrm{Ar}^{+}$laser line with $\lambda=514.5 \mathrm{~nm}$.

\section{Evaluation of single and mixture gas permeation}

For the single gas and mixture gas permeation, the supported zeolite LTA membranes on porous $\alpha-\mathrm{Al}_{2} \mathrm{O}_{3}$ disks were sealed in a permeation module with silicone O-rings. The sweep gas $\mathrm{N}_{2}$ (except for the $\mathrm{N}_{2}$ permeation measurement where $\mathrm{CH}_{4}$ was used as the sweep gas) was fed on the permeate side to keep the concentration of the permeating gas as low as possible thus providing a driving force for permeation. The total pressure on each side of the membrane was atmospheric. The fluxes of feed and sweep gases were determined with mass flow controllers, and a calibrated gas chromatograph (HP6890) was used to measure the gas concentrations (Fig. S2 $\dagger$ ). The separation factor $\alpha_{i, j}$ of a binary mixture permeation is defined as the quotient of the molar ratios of the components $(i, j)$ in the permeate, divided by the quotient of the molar ratio of the components $(i, j)$ in the retentate.

\section{Results and discussion}

The formation of a diisocyanate layer on the $\mathrm{Al}_{2} \mathrm{O}_{3}$ surface after reaction of diisocyanate with a surface hydroxy group was confirmed with Raman spectra. As shown in Fig. 2, all the peaks match well with those of DIC-4 reported previously. ${ }^{43}$ The absorptions of $\mathrm{CH}_{2}$ groups of the aliphatic chain are observed at a high frequency of 2920 and $2850 \mathrm{~cm}^{-1}$ resulting from the 


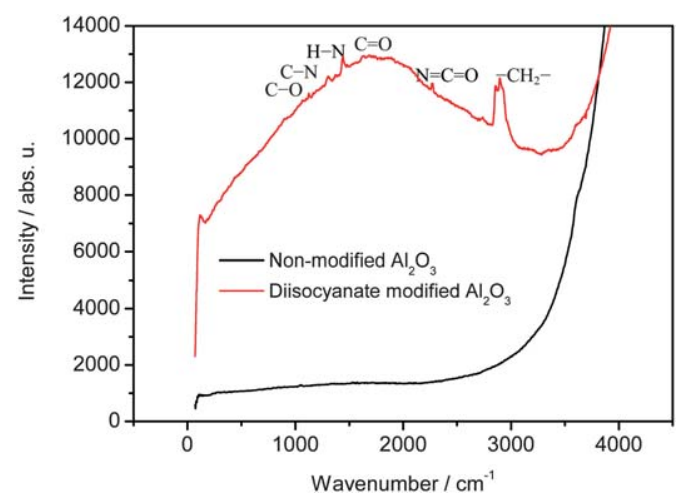

Fig. 2 Raman spectra of non-modified and diisocyanate modified $\mathrm{Al}_{2} \mathrm{O}_{3}$.

asymmetric and symmetric stretching vibrations. The presence of available isocyanate groups is demonstrated with the band at $2276 \mathrm{~cm}^{-1}$ due to the asymmetric stretching vibration of the $\mathrm{N}=\mathrm{C}=\mathrm{O}$ groups. The formation of urethane bonds is indicated with the absorptions at $1695 \mathrm{~cm}^{-1}$ due to the $\mathrm{C}=\mathrm{O}$ stretching vibration, as well as the combined $\mathrm{H}-\mathrm{N}$ bend with a $\mathrm{C}-\mathrm{N}$ stretching vibration located at $1530 \mathrm{~cm}^{-1}$. The $\mathrm{C}-\mathrm{N}$ stretch is found at $1260 \mathrm{~cm}^{-1}$. The lowest frequency absorptions at 1151 $\mathrm{cm}^{-1}$ are attributed to $(\mathrm{O}=) \mathrm{C}-\mathrm{O}$ stretch.

Fig. 3a-c show the SEM top view of the zeolite LTA membrane at different magnifications supported on the DIC-4 functionalized asymmetric macroporous $\alpha-\mathrm{Al}_{2} \mathrm{O}_{3}$ disk. The SEM images indicate that the support surface is totally covered by uniform and compact cubic-shaped crystals, and no visible cracks, pinholes or other macroscopic defects are observed. From the cross-section view shown in Fig. 3d, it can be seen that the membrane is well intergrown with a thickness of about $3.5 \mu \mathrm{m}$. On the contrary, no dense LTA layer can be formed on the non-functionalized $\alpha-\mathrm{Al}_{2} \mathrm{O}_{3}$ disk by in situ growth. The zeolite layer is less intergrown containing loosely packed crystals and a rough layer surface (Fig. S $3 \dagger$ ). It is well recognized that the
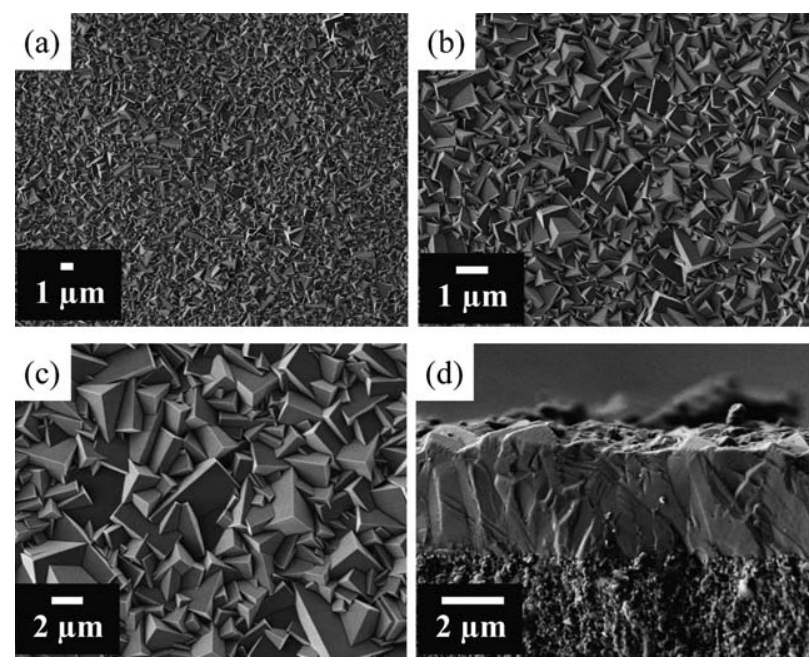

Fig. 3 SEMs of the zeolite LTA membrane prepared on the 1,4-diisocyanate functionalized porous $\alpha-\mathrm{Al}_{2} \mathrm{O}_{3}$ disk. Top view $(\mathrm{a}-\mathrm{c})$ with different magnifications and the cross-section (d). formation of zeolite membranes on supports is a heterogeneous nucleation process, ${ }^{33-35}$ i.e. a homogeneous gel layer is first formed on the support surface for the production of nuclei, followed by crystal growth to form a continuous membrane. However, due to the weak interaction between the molecular precursor species and the support, the heterogeneous nucleation of zeolite on the support surface is poor, which causes problems in the formation of a continuous layer. Therefore, coating of the supports with seed crystals is usually indispensable.

Via urethane bonds as proposed previously, ${ }^{42,43}$ in the present work we use DIC-4 as highly efficient molecular linkers which in situ anchor the LTA nutrients onto the support surface thus promoting the nucleation. The enhancement of nucleation on the DIC-4 modified $\alpha-\mathrm{Al}_{2} \mathrm{O}_{3}$ disk can be deduced from membrane morphology, showing a large number of small and well intergrown crystals (Fig. 3a-c). Actually, a rather continuous layer can be formed on the DIC- 4 modified $\alpha-\mathrm{Al}_{2} \mathrm{O}_{3}$ disk in a rather short synthesis time (Fig. $\mathrm{S} 4 \dagger$ ).

The formation of a pure zeolite LTA membrane with a high degree of crystallinity was confirmed by XRD (Fig. 4), which shows that all peaks match well with those of zeolite LTA powder besides the $\alpha-\mathrm{Al}_{2} \mathrm{O}_{3}$ signals from the support. It should be noted that unlike the monolayer assembly of zeolite crystals by using DIC-4 as covalent linkers, ${ }^{42}$ the zeolite LTA membrane prepared on DIC-4 modified $\alpha-\mathrm{Al}_{2} \mathrm{O}_{3}$ support by in situ hydrothermal synthesis shows no preferential orientation.

It is well known that the nature of the supports and its surface properties have great influence on the layer growth. ${ }^{44-46}$ Fig. 5 shows the SEMs of zeolite LTA films prepared on different nonfunctionalized or DIC-4 functionalized non-porous supports: glass plate, stainless steel disk, and PTFE disk. As shown in Fig. 5, DIC-4 functionalization is necessary to grow continuous LTA layers on stainless steel and PTFE. Only in the case of the glass plate a continuous LTA layer is grown without functionalization due to the high concentration of silanols. After covalent functionalization of the supports by DIC-4 before hydrothermal synthesis, the growth of zeolite LTA is markedly improved, and dense and pure LTA films containing well intergrown cubic crystals can be formed on glass plate, stainless steel and PTFE disks (Fig. 5 and S5-7†).

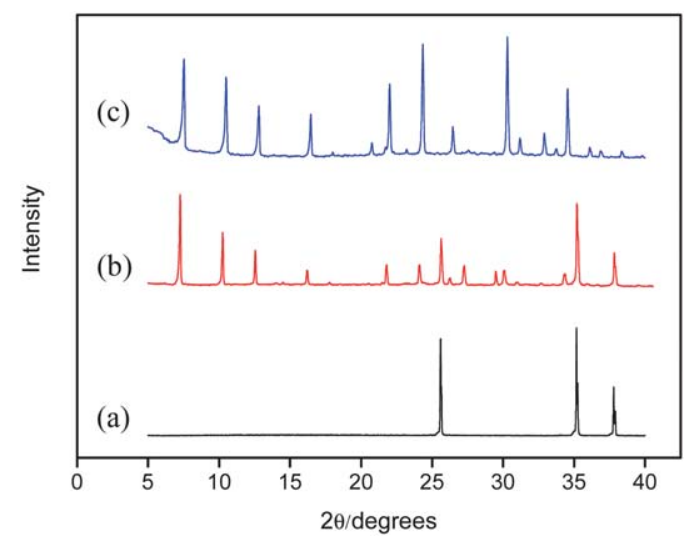

Fig. 4 XRD patterns of the DIC-4 modified $\alpha-\mathrm{Al}_{2} \mathrm{O}_{3}$ support (a), zeolite LTA membrane prepared on DIC-4 modified $\alpha-\mathrm{Al}_{2} \mathrm{O}_{3}$ support (b), and zeolite LTA powder (c). 

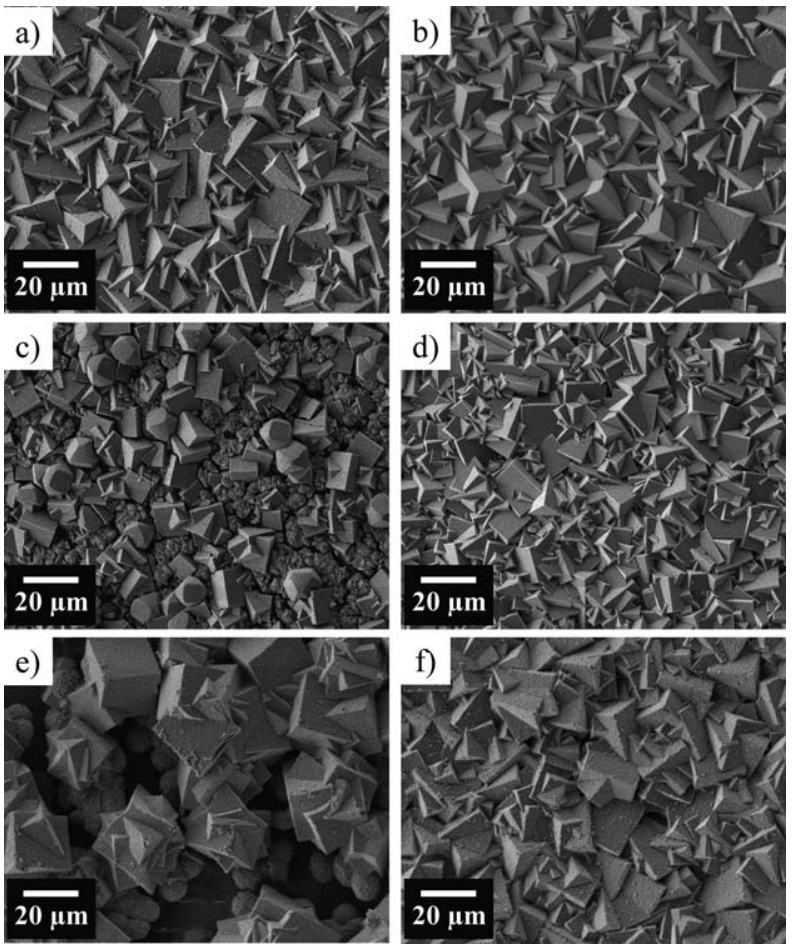

Fig. 5 Top view SEMs of the zeolite LTA membranes prepared on the non-functionalized (a, c, and e) and DIC-4 functionalized (b, d, and f) non-porous supports. (a and b) Glass plate, (c and d) stainless steel disk, and (e and f) polytetrafluoroethylene disk.

The concept of using DIC-4 as molecular binders could be extended from LTA layer growth on flat supports to the growth of dense LTA layers on tubular supports (Fig. S8 $\dagger$ ). From the cross-section of the LTA membrane on the tubular alumina supports (Fig. $\mathrm{S} 8 \mathrm{~b} \dagger$ ), it can be seen that the support pores are filled with zeolite crystals due to the rather large pore size of the support top layer $(\sim 1 \mu \mathrm{m})$ in comparison with the $\alpha-\mathrm{Al}_{2} \mathrm{O}_{3}$ disk $(\sim 0.1 \mu \mathrm{m})$, which results in a sharp border in the latter case between the external supported LTA layer and the support (Fig. 3d). As expected, besides DIC-4, other diisocyanates like DIC-6 can also be used as molecular binders for the facile formation of zeolite LTA membranes. As shown in Fig. S9†, a dense and well intergrown LTA membrane can be formed consistently on the DIC- 6 functionalized $\mathrm{Al}_{2} \mathrm{O}_{3}$ support. Further work is in progress to extend this strategy to prepare other zeolite membranes. It is worth to note that isocyanate compounds can be easily derived from a wide variety of compounds, while reactive silyl compounds can be produced only from olefins, ${ }^{42}$ therefore the present covalent road through urethane bonds is more conveniently applied than silanol linkers that we reported previously. ${ }^{41}$

The zeolite LTA membrane was evaluated by single gas permeation and mixture gas separation. The volumetric flow rates of the single gases $\mathrm{H}_{2}, \mathrm{CO}_{2}, \mathrm{~N}_{2}, \mathrm{CH}_{4}$ and $\mathrm{C}_{3} \mathrm{H}_{8}$ as well as the equimolar binary mixtures of $\mathrm{H}_{2}$ with $\mathrm{CO}_{2}, \mathrm{~N}_{2}, \mathrm{CH}_{4}$ and $\mathrm{C}_{3} \mathrm{H}_{8}$ were measured using the Wicke-Kallenbach technique (Fig. S2†). Fig. 6 shows the permeances of the single gases through the LTA zeolite membrane prepared on DIC-4 modified $\alpha-\mathrm{Al}_{2} \mathrm{O}_{3}$ supports at $20{ }^{\circ} \mathrm{C}$ and 1 bar as a function of the kinetic

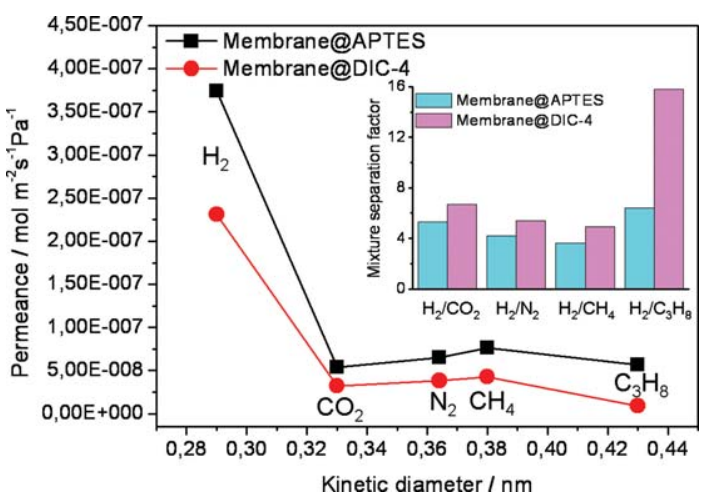

Fig. 6 Single gas permeances of different gases on the zeolite LTA membrane prepared on the DIC-4 functionalized $\mathrm{Al}_{2} \mathrm{O}_{3}$ disks as a function of the gas kinetic diameter at $20^{\circ} \mathrm{C}$ and 1 bar pressure difference. The inset shows the mixture separation factor for $\mathrm{H}_{2}$ over other gases from equimolar mixtures as determined by gas chromatography.

diameters of the permeating molecules. As shown in Fig. 6, the permeance of $\mathrm{C}_{3} \mathrm{H}_{8}$ is much lower than those of the other gases, which is in accordance with the pore size of about $0.4 \mathrm{~nm}$ of zeolite $\mathrm{Na}^{+} \mathrm{LTA}$ (4A). At $20^{\circ} \mathrm{C}$, the ideal separation factors of $\mathrm{H}_{2}$ from $\mathrm{CO}_{2}, \mathrm{~N}_{2}, \mathrm{CH}_{4}$ and $\mathrm{C}_{3} \mathrm{H}_{8}$, determined as the ratio of the single component permeances, are 7.17, 6.02, 5.40, and 25.7, respectively, which exceed the corresponding Knudsen coefficients $\left(4.7,3.7,2.8\right.$ and 4.7) by far, suggesting that the $\mathrm{Na}^{+} \mathrm{LTA}$ zeolite membrane prepared by using DIC- 4 as molecular binders displays hydrogen selectivity with a $\mathrm{H}_{2}$ permeance of $2.3 \times 10^{-7}$ mol m${ }^{-2} \mathrm{~s}^{-1} \mathrm{~Pa}^{-1}$. For comparison, Fig. 6 also shows the permeances of the single gases through the $\mathrm{Na}^{+}$LTA zeolite membranes on APTES modified $\alpha-\mathrm{Al}_{2} \mathrm{O}_{3}$ supports as a function of the kinetic diameters of the permeating molecules. At $20{ }^{\circ} \mathrm{C}$, the ideal separation factors of $\mathrm{H}_{2}$ from $\mathrm{CO}_{2}, \mathrm{~N}_{2}, \mathrm{CH}_{4}$ and $\mathrm{C}_{3} \mathrm{H}_{8}$, are $6.95,5.76,4.89$ and 6.61 , which also exceed the corresponding Knudsen coefficients. However, it is obvious that the $\mathrm{Na}^{+} \mathrm{LTA}$ zeolite membrane prepared on DIC-4 modified $\alpha-\mathrm{Al}_{2} \mathrm{O}_{3}$ supports displays higher separation selectivities than that prepared on APTES modified $\alpha-\mathrm{Al}_{2} \mathrm{O}_{3}$ supports, in particular for the separation of $\mathrm{H}_{2}$ with $\mathrm{C}_{3} \mathrm{H}_{8}$. The enhancement of separation performances is attributed to the stronger binding strength of urethane groups when DIC-4 was used as molecular linkers. As reported previously, ${ }^{42}$ the binding strengths of DIC-4 between the zeolite crystals and glass plates are higher than that of APTES due to the increase in the number of inter-surface molecular binders for DIC-4.

The permeances of $n$ - and $i$-butane through the $\mathrm{Na}^{+} \mathrm{LTA}$ membrane are rather low since both kinetic diameters of $n$ butane $(0.43 \mathrm{~nm})$ and $i$-butane $(0.51 \mathrm{~nm})$ are larger than the pore size of $\mathrm{Na}^{+} \mathrm{LTA}(\sim 0.4 \mathrm{~nm})$. In $\mathrm{Na}^{+}$LTA with a u.c. composition $\mathrm{Na}_{12}\left[\mathrm{Si}_{12} \mathrm{Al}_{12} \mathrm{O}_{48}\right]$, three of the twelve $\mathrm{Na}^{+}$ions are located in the six 8-ring windows between the two u.c. thus reducing the window diameter. After ion exchange of the $12 \mathrm{Na}^{+}$by $6 \mathrm{Ca}^{2+}$, the 6 introduced $\mathrm{Ca}^{2+}$ ions occupy positions near to the cubooctahedra and no cations are present in the 8 membered oxygen rings, leading to a pore size of about $0.5 \mathrm{~nm}$. As shown in Table 1, all single gas permeances of hydrogen, $n$ - and $i$-butane increase when $\mathrm{Na}^{+}$ions were exchanged by $\mathrm{Ca}^{2+}$. At $20^{\circ} \mathrm{C}$ and 1 
Table 1 Comparison of single gas separation performances of the $\mathrm{Ca}^{2+}$ LTA zeolite membrane ${ }^{a}$ with $\mathrm{Na}^{+} \mathrm{LTA}$ membrane prepared on the DIC-4 functionalized $\alpha-\mathrm{Al}_{2} \mathrm{O}_{3}$ disks

\begin{tabular}{|c|c|c|c|c|c|}
\hline \multirow[b]{2}{*}{ Membrane } & \multicolumn{5}{|c|}{ Single gas separation performances } \\
\hline & Hydrogen & $n$-Butane & $i$-Butane & $\mathrm{H}_{2} / n$-Butane & n/i-Butane \\
\hline $\mathrm{Na}^{+} \mathrm{LTA}$ & 241 & 3.85 & 0.27 & 60 & 14.3 \\
\hline $\mathrm{Ca}^{2+} \mathrm{LTA}$ & 527 & 102 & 0.73 & 5.2 & 140 \\
\hline
\end{tabular}

${ }^{a}$ The $\mathrm{Ca}^{2+}$ exchange was completed by immersing the $\mathrm{Na}^{+} \mathrm{LTA}$ membrane in $0.1 \mathrm{M} \mathrm{CaCl}_{2}$ solution at $20{ }^{\circ} \mathrm{C}$ for $24 \mathrm{~h} .{ }^{b}$ The permeances of single gas were measured by using a soap-film method at $20^{\circ} \mathrm{C}$.

bar, the single component permeances of $n$ - and $i$-butane through the $\mathrm{Ca}^{2+} \mathrm{LTA}$ membrane are found to be $1.02 \times 10^{-7}$ and $0.73 \times 10^{-9} \mathrm{~mol} \mathrm{~m}^{-2} \mathrm{~s}^{-1} \mathrm{~Pa}^{-1}$, respectively. Therefore, for the gas pair $n / i$-butane, a high ideal separation factor defined as ratio of the single component fluxes of 140 can be derived for the $\mathrm{Ca}^{2+}$ LTA membrane.

The molecular sieve performance of the zeolite $\mathrm{Na}^{+} \mathrm{LTA}$ membrane prepared on DIC-4 modified $\alpha-\mathrm{Al}_{2} \mathrm{O}_{3}$ disks was also confirmed by the separation of equimolar mixtures of $\mathrm{H}_{2}$ with $\mathrm{CO}_{2}, \mathrm{~N}_{2}, \mathrm{CH}_{4}$ and $\mathrm{C}_{3} \mathrm{H}_{8}$ at $20^{\circ} \mathrm{C}$ and 1 bar. As shown in the inset of Fig. 6, for the $1: 1$ binary mixtures, the mixture separation factors of $\mathrm{H}_{2} / \mathrm{CO}_{2}, \mathrm{H}_{2} / \mathrm{N}_{2}, \mathrm{H}_{2} / \mathrm{CH}_{4}$ and $\mathrm{H}_{2} / \mathrm{C}_{3} \mathrm{H}_{8}$, determined as the molar ratios in permeate and retentate, are 6.7, 5.4, 4.9 and 15.8, which are higher than those from the $\mathrm{Na}^{+}$LTA zeolite membrane prepared on the APTES modified $\alpha-\mathrm{Al}_{2} \mathrm{O}_{3}$ supports (5.3, 4.2, 3.6 and 6.4) and higher than the corresponding Knudsen coefficients $(4.7,3.7,2.8$ and 4.7). It is found that DIC-4 functionalization of supports is helpful to eliminate the influence of the surface chemistry and thus enhance the reproducibility of the membrane preparation (Table $\mathrm{S} 1 \dagger$ ).

\section{Conclusions}

In conclusion, in the present work, a facile seeding-free synthesis method was developed for the reproducible preparation of dense zeolite LTA layers on different covalently functionalized supports by using the diisocyanate DIC-4 as a molecular binder, which is helpful to in situ anchor the LTA nutrients onto the support surface during the hydrothermal synthesis of zeolite LTA layers. Through the urethane bonds formed in the reaction of isocyanate groups with surface hydroxyls, DIC-4 can act as a molecular binder between the LTA nutrients and the support thus promoting the nucleation and facilitating the formation of a uniform, well intergrown and phase-pure LTA membrane. The zeolite LTA membranes prepared on DIC-4 modified porous $\alpha$ $\mathrm{Al}_{2} \mathrm{O}_{3}$ disks display higher separation selectivities than those ones prepared on APTES modified $\alpha-\mathrm{Al}_{2} \mathrm{O}_{3}$ disks due to the stronger binding strength of urethane bonds in comparison with that of the bonds linking to silyl compounds. For binary mixtures separation, through the $\mathrm{Na}^{+} \mathrm{LTA}$ membrane at $20^{\circ} \mathrm{C}$ and 1 bar, the mixture separation factors of $\mathrm{H}_{2} / \mathrm{CO}_{2}, \mathrm{H}_{2} / \mathrm{N}_{2}, \mathrm{H}_{2} /$ $\mathrm{CH}_{4}$ and $\mathrm{H}_{2} / \mathrm{C}_{3} \mathrm{H}_{8}$ are found to be 6.7, 5.4, 4.9 and 15.8, respectively, which are higher than those from the corresponding Knudsen coefficients. Further, relative high $\mathrm{H}_{2}$ permeances of about $2.3 \times 10^{-7} \mathrm{~mol} \mathrm{~m}^{-2} \mathrm{~s}^{-1} \mathrm{~Pa}^{-1}$ have been obtained. After pore opening of the $\mathrm{Na}^{+}$LTA membrane by $\mathrm{Ca}^{2+}$ ion exchange, an ideal separation factor of 140 for $n / i$-butane is determined.

\section{Acknowledgements}

This work was financially supported by DFG (Ca147/11-3), as a part of the European joint research project "International Research Group: Diffusion in Zeolites" of DFG, CNRS and EPSRC. Dr A. Feldhoff is thanked for support in electron microscopy.

\section{References}

1 J. Caro and M. Noack, Microporous Mesoporous Mater., 2008, 115, 215.

2 A. Tavolaro and E. Drioli, Adv. Mater., 1999, 11, 975.

3 E. E. McLeary, J. C. Jansen and F. Kapteijn, Microporous Mesoporous Mater., 2006, 90, 198.

4 D. Casanave, A. Giroir-Fendler, J. Sanchez, R. Loutaty and J. A. Dalmon, Catal. Today, 1995, 25, 309.

5 M. Yu, J. L. Falconer, T. J. Amundsen, M. Hong and R. D. Noble, Adv. Mater., 2007, 19, 3032.

6 Z. Wang, H. Wang, A. Mitra, L. Huang and Y. Yan, Adv. Mater., 2001, 13, 746 .

7 Y. S. Yan, M. E. Davis and G. R. Gavalas, Ind. Eng. Chem. Res., $1995,34,1652$.

8 J. M. van de Graaf, E. van der Bijl, A. Stol, F. Kapteijn and J. A. Moulijn, Ind. Eng. Chem. Res., 1998, 37, 4071.

9 M. Kanezashi, J. O'Brien-Abraham, Y. S. Lin and K. Suzuki, AIChE $J ., 2008, \mathbf{5 4}, 1478$.

10 A. Huang, F. Liang, F. Steinbach, T. M. Gesing and J. Caro, J. Am. Chem. Soc., 2010, 132, 2140.

11 A. Huang and J. Caro, Chem. Commun., 2010, 46, 7748.

12 A. Huang and J. Caro, Chem. Mater., 2010, 22, 4353.

13 K. Aoki, K. Kusakabe and S. Morooka, J. Membr. Sci., 1998, 141, 197.

14 X. C. Xu, W. S. Yang, J. Liu and L. W. Lin, Adv. Mater., 2000, 12, 195.

15 K. Kusakabe, T. Kuroda, A. Murata and S. Morooka, Ind. Eng. Chem. Res., 1997, 36, 649.

16 V. Nikolakis, G. Xomeritakis, A. Abibi, M. Dickson, M. Tsapatsis and D. G. Vlachos, J. Membr. Sci., 2001, 184, 209.

17 M. A. Carreon, S. Li, J. L. Falconer and R. D. Noble, J. Am. Chem. Soc., 2008, 130, 5412.

18 M. A. Carreon, S. Li, J. L. Falconer and R. D. Noble, Adv. Mater., 2008, 20, 729.

19 S. Mintova, S. Mo and T. Bein, Chem. Mater., 1998, 10, 4030

20 J. J. Jafar and M. Budd, Microporous Mater., 1997, 12, 305.

21 M. Kondo, M. Komori, H. Kita and K. I. Okamota, J. Membr. Sci., 1997, 133, 133.

22 A. Huang and W. S. Yang, Sep. Purif. Technol., 2007, 56, 158.

23 D. Shah, K. Kissick, A. Ghorpade, R. Hannah and D. Bhattacharyya, J. Membr. Sci., 2000, 179, 185.

24 W. Zhu, L. Gora, A. W. C. van den Berg, F. Kapteijn, J. C. Jansen and J. A. Moulijn, J. Membr. Sci., 2005, 253, 7.

25 Q. Ge, Z. Wang and Y. Yan, J. Am. Chem. Soc., 2009, 131, 17056. 
26 Y. Morigami, M. Kondoa, J. Abe, H. Kita and K. Okamoto, Sep. Purif. Technol., 2001, 25, 251.

27 K. Sato, K. Aoki, K. Sugimoto, K. Izumi, S. Inoue, J. Saito, S. Ikeda and T. Nakane, Microporous Mesoporous Mater., 2008, 115, 184.

28 X. Yin, G. Zhu, W. Yang, Y. Li, G. Zhu, R. Xu, J. Sun, S. Qiu and R. Xu, Adv. Mater., 2005, 17, 2006.

29 M. Noack, P. Kölsch, A. Dittmar, M. Stöhr, G. Georgi, M. Schneider, U. Dingerdissen, A. Feldhoff and J. Caro, Microporous Mesoporous Mater., 2007, 102, 1.

30 J. Caro, D. Albrecht and M. Noack, Sep. Purif. Technol., 2009, 66 143.

31 S. Yamazaki and K. Tsutsumi, Microporous Mesoporous Mater., 2000, 37, 67.

32 S. Li, Z. J. Li, K. N. Bozhilov, Z. W. Chen and Y. S. Yan, J. Am Chem. Soc., 2004, 126, 10732.

33 G. J. Myatt, P. M. Budd, C. Price and S. W. Carr, J. Mater. Chem., 1992, 2, 1103.

34 J. H. Koegler, H. van Bekkum and J. C. Jansen, Growth model of oriented crystals of zeolite Si-ZSM-5, Zeolites, 1997, 19, 262.

35 Y. S. Li, J. Liu and W. S. Yang, J. Membr. Sci., 2006, 281, 646.
36 M. C. Lovallo and M. Tsapatsis, AIChE J., 1996, 42, 3020.

37 Z. Lai, G. Bonilla, I. Diaz, J. Nery, K. Sujaoti, M. A. Amat, E. Kokkoli, O. Terasaki, R. W. Thompson, M. Tsapatsis and D. G. Vlachos, Science, 2003, 300, 456.

38 J. Choi, S. Ghosh, Z. Lai and M. Tsapatsis, Angew. Chem., Int. Ed., 2006, 45, 1154.

39 A. Huang, Y. S. Lin and W. S. Yang, J. Membr. Sci., 2004, 245, 41.

40 B. Zhang, M. Zhou and X. Liu, Adv. Mater., 2008, 20, 2183.

41 A. Huang, F. Liang, F. Steinbach and J. Caro, J. Membr. Sci., 2010, $350,5$.

42 Y. S. Chun, K. Ha, Y.-J. Lee, J. S. Lee, H. S. Kim, Y. S. Park and K. B. Yoon, Chem. Commun., 2002, 1846.

43 E. Biemmi and T. Bein, Langmuir, 2008, 24, 11196.

44 J. L. H. Chau, C. Tellez, K. L. Yeung and K. Ho, J. Membr. Sci., 2000, 164, 257.

45 R. Lai, Y. S. Yan and G. R. Gavalas, Microporous Mesoporous Mater., 2000, 37, 9 .

46 A. W. C. van den Berg, L. Gora, J. C. Jansen, M. Makkee and Th. Maschmeyer, J. Membr. Sci., 2003, 224, 29. 